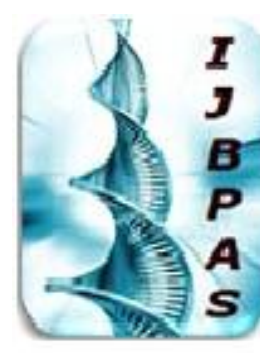

International Journal of Biology, Pharmacy and Allied Sciences (IJBPAS) 'A Bridge Betusen Caboratory and QRado'

\author{
WwW.ijbpas,com
}

\title{
PHYTOCHEMICALS AND BIOACTIVITIES OF TALAHIB (Saccharum spontaneum) ROOTS EXTRACT
}

\section{ERVEE P. LANDINGIN, GABRIELLE T. SALAMANCA, MICA AUBREY C.}

BAUTISTA, EFRAIM JOSE H. LIWANAG, RICH MILTON R. DULAY*

Bioassay Laboratory, Department of Biological Sciences, College of Arts and Sciences, Central

Luzon State University, Science City of Munoz, Nueva Ecija, 3120 Philippines

*Corresponding Author, E-mail: richmiltondulay@clsu.edu.ph

Received $15^{\text {th }}$ Feb. 2018; Revised $14^{\text {th }}$ March. 2018; Accepted $10^{\text {th }}$ April 2018; Available online $1^{\text {st }}$ June 2018

DOI: $\underline{\text { https://doi.org/10.31032/IJBPAS/2018/7.6.4480 }}$

\begin{abstract}
This paper reported the phytochemical constituents and biological activities of talahib (Saccharum spontaneum) roots. Phytochemical screening revealed that S. spontaneum roots contain phenols, triterpenes, essential oils, steroids, anthraquinones, coumarin, anthrones, flavonoids, and alkaloids. The antioxidant and antibacterial activities of the ethanol extract were also determined. It was found out that the ethanol extract exhibited $68.97 \%$ scavenging activity against 1, 1-Diphenyl-2-picrylhydrazyl (DPPH) free radicals. However, the extract did not show inhibitory activity against Pseudomonas aeruginosa. Thus, S. spontaneum roots could be a source of bioactive compounds with biological activities such as antioxidant.
\end{abstract}

Keywords: Phytochemical screening, antioxidant, Pseudomonas aeruginosa INTRODUCTION

Saccharum spontaneum, commonly known as talahib, is a type of perennial grass that is coarse and erect. It grows up to $3.5 \mathrm{~m}$ and has linear leaves that are about $1 \mathrm{~m}$ long and 6 to $15 \mathrm{~mm}$ wide. In the Philippines, root decoction is used as a diuretic and for fever.
In other countries such as in Bengal, $S$. spontaneum roots are used as galactagogue [1]. S. spontaneum exhibits antioxidative [2], anti-diarrhoeal, and CNS depressant properties [3], and it could also be used in cellulose production [4]. Its roots are also 
used as astringent, emollient, refrigerant, diuretic, purgative, tonic, aphrodisiac and useful in treatment of dyspepsia, burning sensation, piles and sexual weakness, it also contained minerals, organic acids, flavonoids and phenolic compounds which was found to possess antioxidant, mast cells calming effects, the roots are also used as food or parts of food that could deliver medical health aids including action and prevention of illnesses [5].

Phytochemicals are bioactive compounds found in plants or plant-based products. These compounds are reported to have numerous of biological activities depending on the type of phytochemicals present. Some of these activities include insecticidal, phytotoxic, fungitoxic, nematocidal, antibacterial, antioxidant activities, some are for the plants defensive mechanism against herbivores and some are for the plants own growth, reproduction and responses to several abiotic and biotic stresses $[\mathbf{6}, 7,8,9$, 10, 11, 12]. These phytochemicals can be extracted and screened at various methods for pharmacological investigation of certain plants.

Antioxidants, on the other hand, are substances that are found in plants. They could inhibit oxidation and remove potentially damaging effect of oxidizing agents in a living cell or organism. Antioxidants could prevent various human diseases like Alzheimer's disease, atherosclerosis, adult respiratory distress syndrome, cancer, and diabetes [13]. DPPH assay is a much more stable method compared to the other methods. It is an easier and faster way to determine the antioxidant activity of a compound or plant extract. Unlike other methods, sample polarity is not necessary for the exhibited activity using DPPH method [14].

This study reported the phytochemical constituents and biological activities of $S$. spontaneum roots, specifically, the radical scavenging activity and the antibacterial activity against $P$ seudomonas aeruginosa.

\section{MATERIALS AND METHODS}

\section{Collection of S. spontaneum Roots}

The root samples of $S$. spontaneum were collected from Bagong Sikat, Science City of Muñoz, Nueva Ecija, Philippines. The collected plant roots were washed with tap water and were air dried in room temperature for 3 weeks. After drying, the air dried roots were then pulverized using a blender.

\section{Preparation of Ethanolic Extract}

The pulverized root sample (20 g) was soaked in $95 \%$ ethanol for 48 hours. Then the extract was filtered using Whatman filter 
paper no. 1. The filtrates were concentrated in rotary evaporator at $40^{\circ} \mathrm{C}$ until dryness.

\section{Phytochemical Screening}

Phytochemical screening was carried out to detect secondary metabolites present. The plant extract was spotted on marked and labeled TLC (Thin Layer Chromatography) 7 $\mathrm{x} 4 \mathrm{~cm}$, and was developed in acetatemethanol (7:3) mixture in the developing chamber. The spots for certain metabolite were visualized on the TLC plates and were exposed under UV light and hot plate to check the separation of the different compounds.

For typical visualization of secondary metabolites, vanillin-sulfuric acid reagents were used. This solution showed the presence of phenols, sterols, triterpenes, and essential oils. Methanolic potassium hydroxide was used to test anthraquinones, coumarins and anthranones while phenolic compounds and tannins were detected through the use of potassium ferricyanide-ferric chloride reagent. Dragendorff's reagent was utilized to spot alkaloids and antimony (III) was used to detect the presence of flavonoids [15].

\section{DPPH Radical Scavenging Assay}

The concentrated extract was used to make a stock solution and aliquot was taken to make $1000 \mathrm{ppm}$ dilution and $1000 \mathrm{ppm}$ of catechin as control $(1 \mathrm{mg} / \mathrm{mL})$. One millilitre of prepared stock solution was mixed with four $\mathrm{mL}$ of $0.1 \mathrm{mM}$ DPPH solution in separate plastic cuvette. Reactions were done in triplicate. The prepared mixtures were incubated in the dark at $37^{\circ} \mathrm{C}$ for 30 minutes. The absorbance readings were monitored at $517 \mathrm{~nm}$ using a UV VIS spectrophotometer. A lower absorbance of the reaction mixture indicated higher free radical scavenging activity. The radical scavenging activities were compared to the activity of the control catechin. The ability to scavenge the DPPH radical was calculated using the formula: $(\mathrm{A} 0-\mathrm{A} 1) / \mathrm{A} 0] \times 100$, where $\mathrm{A} 0$ was the absorbance of the control which is the DPPH without the test sample and A1 was the absorbance of the test sample containing the mixture of the DPPH and the sample. Catechin was used as the positive control [16].

\section{Antibacterial Assay}

A bacterial suspension of Pseudomonas aeruginosa was provided by Immaculate Concepion Medical Center and was subcultured into a fresh nutrient broth. The bacterial suspension was adjusted to 0.5 McFarland standard and measured using a turbidometer. A sterile cotton swab was dipped into the bacterial suspension and aseptically spread onto the surface of the plated nutrient agar. After swabbing, blot- 
dried paper discs (6mm diameter) previously soaked in the different treatments namely; $S$. spontaneum root extract, streptomycin (positive control), and 95\% ethanol (negative control) were placed equidistantly on the media with bacteria. Plates were incubated at room temperature and the diameter zone of inhibition, if any, was measured after 24 hours.

\section{RESULTS AND DISCUSSION}

\section{Phytochemical Composition}

Phytochemical screening using TLC spot method of the ethanolic extract of $S$. spontaneum roots revealed the presence of essential oils, phenols, triterpenes, steroids, anthraquinones, coumarins, anthrones, flavonoids and alkaloids (Table 1). Similarly, these phytochemicals were also detected in the study of Khalid and Siddiqui [5], along with the additional presence of carbohydrates, tannins, and terpenoids. Sathya and
Kokilavani [17] reported the qualitative analysis of phytochemicals in the root extract of $S$. spontaneum using different types of solvents, and they found out that methanolic and ethanolic root extracts of the plant showed more phytochemicals, specifically the presence of tannins, steroids and glycosides.

Most of these phytochemicals have medicinal properties. Edeoga and Enata [18] reported that alkaloids were powerful pain reliever and topical anaesthetic in ophthalmology. Flavonoids, on the other hand, were reported by Woznicka et al. [19] to exhibit cardioprotection, anticancer, and anti-inflammatory properties. Anthraquinones shows potential anti-cancer and theraputic properties [20]. Triterpenes have potential in combating immune diseases [21], while coumarins have anticoagulant properties and are potent antiinflammatory drugs [22].

\begin{tabular}{|c|c|}
\hline \multicolumn{2}{|c|}{ Table 1: Phytochemical constituents of S. spontaneum roots } \\
\hline Phytochemicals & S. spontaneum roots \\
\hline Essential oils & Present \\
\hline Phenols & Present \\
\hline Triterpenes & Present \\
\hline Steroids & Present \\
\hline Anthraquinones & Present \\
\hline Coumarins & Present \\
\hline Anthrones & Present \\
\hline Flavonoids & Present \\
\hline Alkaloids & Present \\
\hline
\end{tabular}




\section{DPPH Radical Scavenging Assay}

Antioxidants are substances that inhibit oxidation that causes several physiologic diseases. DPPH assay is one of the methods used in determining the antioxidant properties of compounds or substances. This study determined the radical scavenging activity of $S$. spontaneum root extract and the result is shown in Table 2. It can be seen that the radical scavenging activity of the root extract (68.97\%) was higher compared to the radical scavenging activityof catechin (67.37\%). Similarly, Sylvie et al. [23] reported that the three extracts of plants; Acalypha racemosa, Garcinia lucida and Hymeno cardialyrata have higher scavenging activity when compared to catechin. In the contrary, Khalid et al. [2] stated that the RSA of ethanolic extract of $S$. spontaneum roots was significantly lower than ascorbic acid, but found comparable to each other. In addition, Ripa et al. [24] showed that crude chloroform extract of $S$. spontaneum flower revealed antioxidant activity with the IC50 value of $43.04 \mu \mathrm{g} / \mathrm{ml}$.

In this study, anthrones, flavonoids, and phenols were detected in the roots. Yen et al. [25] reported that anthrone exhibited antioxidant activity by inhibition of peroxidation of linoleic acid and revealed that strong activity exposed by anthrone can be associated with its reducing power and scavenging effects on hydroxyl radicals. However, flavonoids have antioxidant and antiproliferative effect especially in metabolic systems [26]. Moreover, powerful antioxidant activities of phenolic compounds of olive oil were reported by Visioli et al. [27]. The presence of these three phytochemicals could make the ethanolic root extract of $S$. spontaneum a good antioxidant drug.

\begin{tabular}{|l|c|}
\hline \multicolumn{2}{|c|}{ Table 2. Radical scavenging activity of root extract of S. spontaneum } \\
\hline Treatment & Radical Scavenging Activity (\%) \\
\hline S. spontaneum roots & 68.97 \\
\hline Cathechin (control) & 67.37 \\
\hline
\end{tabular}

\section{Antibacterial Assay}

The ethanolic extract of $S$. spontaneum roots was also assayed for its antibacterial activity against $P$. aeruginosa. Based on the result, the extract did not show any inhibitory activity against the bacterial pathogen used. Similarly, Lapuz et al. [28] revealed that the crude ethanolic extract of $S$. spontaneum also did not inhibit the growth of $P$. aeruginosa using the four concentrations $(0.5 \%, 1.0 \%$, $1.5 \%$ and $2.0 \%$ ). However, methanolic crude extract of $S$. spontaneum $(150 \mathrm{mg} / \mathrm{ml})$ inhibited the growth of $P$. aeruginosa with $15.20 \mathrm{~mm}$ diameter zone of inhibition (Hussain et al., 2014). These findings strongly suggest that the anti- $P$. aeruginosa 
effect of $S$. spontaneum root is solvent dependent. Steroids and essential oil which are found present in S. spontaneum roots are known for their antibacterial potential. Steroids exhibited antibacterial activity with a minimal inhibitory concentration of 32 $\mu \mathrm{g} / \mathrm{ml}$ against Pasteurella multocida and Staphylococcus aureus [11]. Moreover, essential oils have means of action which includes several targets in bacterial cell [12]. Thus, the negative inhibitory effect of the extract could be explained by low amount of these two phytochemicals or could be due to the strong resistance of the tested bacterial pathogen.

\section{CONCLUSION}

Based on the significant results, it can be therefore concluded that $S$. spontaneum roots contain active phytochemicals such as essential oils, phenols, triterpenes, steroids, anthraquinones, coumarins, anthrones, flavonoids and alkaloids, which play significant roles on the biological activities such as antioxidant.

\section{REFERENCES}

[1] Stuart Jr GU. (2015). Talahib. Retrieved February 22, 2018, from Philippine Medicinal Plants: http://www.stuartxchange.org/Talahib.html

[2] Khalid M, Siddiqui HH, Freed S. (2011). Free radical scavenging and total phenolic content of Saccharum spontaneum L. root extracts. International Journal of Research in Pharmacy and Chemistry, 1(4), 11601166.

[3] Vhuiyan MMI, Biva IJ, Saha MR, Islam MS. (2008). Anti-diarrhoeal and CNS depressant activity of methanolic extract of Saccharum spontaneum Linn. Stamford Journal of Pharmaceutical Sciences, 1(1\&2), 63-68.

[4] Ilyas U, Ahmed S, Majeed A, Nadeem M. (2012). Biohydrolysis of Saccharum spontaneum for cellulase production by Aspergillus terreus. African Journal of Biotechnology, 11(21), 4914-4920.

[5] Khalid M, Siddiqui HH. (2011). Pharmacognostical evaluation and qualitative analysis of Saccharum spontaneum (L.) root. International Journal of Pharmaceutical Sciences and Drug Research, 3(4), 338-341.

[6] Aldred EM. (2009). Pharmacology: A Handbook for Complementary Healthcare Professionals. New York: Churchill Livingstone, 149-166.

[7] Vriet C, Russinova E, Reuzeau C. (2012). Boosting crop yields with plant steroids. The Plant Cell, 842-857.

[8] Georges K, Jayaprakasam B, Dalavoy SS, Nair MG. (2004). Pest-managing 
activities of plant extracts and anthraquinones from Cassia nigricans from Burkina Faso. Journal of Ethnopharmacology, 351-355.

[9] Razavi SM. (2011). Plant Coumarins as Allelopathic Agents. International Journal of Biological Chemistry, 86-90.

[10] Aniszewski T. (2007). The Ecological Role of Alkaloids. Secrets of life: Alkaloid Chemistry, Biological Significance, Applications and Ecological Role. 205-233

[11] Dogan A, Otlu S, Celebi O, Aksu Kilicle P, Gulmez Saglam A, Dogan ANC, Mutlu N. (2017). An investigation of antibacterial effects of steroids. Turkish Journal of Veterinary and Animal Sciences, 41, 302-305.

[12] Bakkali F, Averbeck S, Averbeck D, Idaomar M. (2008). Biological effects of essential oils - A review. Food and Chemical Toxicology, 446-475.

[13] Chennupati S, Valluru S, Bhogavalli P. (2012). Studies on antioxidant capacity of petroleum ether and acetone extracts of Pleurotus florida. Asian Journal of Biochemical and Pharmaceutical Research, 2(2), 82-88.

[14] Koleva II, van Beek TA, Linssen JPH, de Groot A, Evstatieva LN. (2002). Screening of plant extracts for antioxidant activity: a comparative study on three testing methods. Phytochemical Analysis, 13, 8-17.

[15] Guevarra BQ. (2005). A guidebook to plant screening: phytochemical and biological. Manila: UST Publishing House

[16] Kolak U, Osturk M, Ozgokce F, Ulubelen A. (2006). Norditerpene alkaloids from Delphenium linearilobum and antioxidant activity. Phytochemistry, 67, 2170-2175.

[17] Sathya M, Kokilavani R. (2013). Phytochemical screening and in vitro antioxidant activity of Saccharum spontaneum Linn. International Journal of Pharmaceutical Sciences Review and Research, 18(1), 75-79.

[18] Edeoga H, Enata D. (2001). Alkaloids, tannins and saponins content of some medicinal plants. Journal of Medical and Aromatic Plant Science, 23, 344-349.

[19] Woznicka E, Kuzniar A, Nowak D, Nykiel E, Kopacz M, Gruszecka, J, Golec K. (2013). Comparative study on the antibacterial activity of some flavonoids and their sulfonic derivativess. Acat poloniae Pharmaceutica-Drug Research, 70(3), 567-71.

[20] Huang Q, Lu G, Shen H, Chung MC, Ong CN. (2007). Anti-cancer properties 
of anthraquinones from rhubarb.

Medicinal Research Reviews, 27, 609630.

[21] Ríos JL. (2010). Effects of triterpenes on the immune system. Journal of Ethnopharmacology, 128(1), 1-14.

[22] Goodman, Gilman's. (2006). The pharmacological basis of therapeutics: blood coagulation and anti-coagulant, thrombolytic and anti-platelet drugs.1325-1328.

[23] Sylvie DD, Anatole PC, Cabral BP, Veronique PB. (2014). Comparison of in vitro antioxidant properties of extracts from three plants used for medical purpose in Cameroon: Acalypha racemosa, Garcinia lucida and Hymeno cardialyrata. Asian Pacific Journal of Tropical Biomedicine, 4(2), S625-S632.

[24] Ripa FA, Haque M, Imran-Ul-Haque M. (2009). In vitro antimicrobial, cytotoxic and antioxidant activity of flower extract of Saccharum spontaneum Linn. European Journal of Scientific Research, 30(3), 478-483.

[25] Yen GC, Duh PD, Chuang DY. (2000). Antioxidant activity of anthraquinones and anthrone. Food Chemistry, 437-441.

[26] Middleton E, Kandaswami C, Theoharides TC. (2000). The effects of plant flavonoids on mammalian cells: implications for inflammation, heart disease, and cancer. Pharmacological Reviews, 673-751.

[27] Visioli F, Poli A, Gall C. (2002), Antioxidant and other biological activities of phenols from olives and olive oil. Medicinal Research Reviews, $22,65-75$.

[28] Lapuz AMR, Arabiran RDA, Sembrano TM, Albaniel JR, Paet JC, Maini HA. (2016). Preformulation and evaluation of antibacterial and anti-Inflammatory activities of Saccharum spontaneum Linne root extract cream. International Journal of Chemical Engineering and Applications, 7(3), 204-208.

[29] Hussain M, Khan MRU, Raza SM, Aziz A, Hazoor B, Majeed A, Mumtaz F. (2014). Assessment of antibacterial potential of Saccharum spontaneum Linn. (familly: Poaceae), against different pathogenic microbes- an in vitro study. Journal of Pharmacy and Alternative Medicine, 3(3), 36-41. 
